\title{
Circular and square slender concrete-filled tubular columns under large eccentricities and fire
}

\author{
A. Espinos ${ }^{\text {a* }}$, M. L. Romero ${ }^{\text {a }}$, E. Serra ${ }^{\text {a }}$, A. Hospitaler ${ }^{\text {a }}$ \\ ${ }^{a}$ Instituto de Ciencia y Tecnología del Hormigón (ICITECH), \\ Universitat Politècnica de València, Valencia, Spain \\ *Corresponding author.e-mail address: aespinos@mes.upv.es
}

\begin{abstract}
Previous investigations have revealed the unsafety of the current calculation methods in Eurocode 4 for evaluating the fire resistance of concrete-filled steel tubular (CFST) columns, which has given place to a movement in Europe for correcting the existing methods and developing new design rules. In order to support the development of new guidance, further experimental research is needed, especially concerning slender columns and large eccentricities. In this paper, the results of a series of fire tests on slender CFST columns of different section shape (circular and square) subjected to large eccentricities are presented. The influence of the cross-section shape, load eccentricity and percentage of reinforcement on the response of these columns at elevated temperatures is studied in this paper, focusing on the effect of large eccentricities combined with high slenderness. On the basis of the experimental results, the current design rules in Eurocode 4 are assessed, and a previous calculation method developed by the authors is also evaluated.
\end{abstract}

Keywords: Fire resistance; Concrete-filled tubular columns; Large eccentricities; Slender columns; Eurocode 4; Simple calculation model 


\section{NOTATION}

$A_{i} \quad$ Cross-sectional area of the of the part $i$ of the composite section

$A_{m} / V \quad$ Section factor

$B \quad$ Width of the square section

CFST Concrete-filled steel tube

$D$

Outer diameter of the circular section

$e$

Load eccentricity

$E_{a, \theta} \quad$ Modulus of elasticity of structural steel at the temperature $\theta$

$E_{c, s e c, \theta} \quad$ Secant modulus of concrete at the temperature $\theta$

$E_{s, \theta} \quad$ Modulus of elasticity of reinforcing steel at the temperature $\theta$

$(E I)_{f i, e f f} \quad$ Effective flexural stiffness in the fire situation

EC4 Eurocode 4

$f_{\mathrm{c}} \quad$ Compressive cylinder strength of concrete at room temperature (test date)

$f_{\mathrm{s}} \quad$ Yield strength of reinforcing steel at room temperature

$f_{\mathrm{y}} \quad$ Yield strength of structural steel at room temperature

$I_{i, \theta} \quad$ Second moment of area of the part $i$ of the cross-section at the temperature $\theta$

$\ell_{\theta} \quad$ Buckling length of the column in the fire situation

$N \quad$ Test load

$N_{f i, R d} \quad$ Design axial buckling load in the fire situation

$N_{f i, R d, \delta} \quad$ Design axial buckling load in the fire situation in case of eccentric load

$N_{R d} \quad$ Design axial buckling load at room temperature

$N_{R d, \delta} \quad$ Design axial buckling load at room temperature in case of eccentric load

$t \quad$ Steel tube wall thickness

L Column length

$\varphi_{i, \theta} \quad$ Reduction coefficient depending on the effect of thermal stresses

$\varphi_{s} \quad$ Reduction coefficient depending on the percentage of reinforcement

$\varphi_{\delta} \quad$ Reduction coefficient depending on the eccentricity

$\rho \quad$ Percentage of reinforcement

$\bar{\lambda} \quad$ Relative slenderness at room temperature

$\bar{\lambda}=\sqrt{N_{p l} / N_{c r}}=\sqrt{\left(A_{c} f_{c}+A_{a} f_{y}+A_{s} f_{s}\right) /\left[\left(\pi^{2} E I\right) / L^{2}\right]}$ 


\section{INTRODUCTION}

Concrete-filled steel tubular (CFST) columns make use of the combined action of steel and concrete, showing an ideal structural performance. While the steel tube confines the concrete core enhancing its compressive strength, the concrete core prevents the steel tube wall from local buckling.

The fire resistance of CFST columns subjected to concentric axial loads has been widely studied through experimental testing in the framework of the research projects from CIDECT [1][2][3] and National Research Council of Canada [4][5][6], or those carried out at Fuzhou University (China) by Han and co-workers [7], researchers from the University of Seoul (Korea) [8] and the authors of this paper [9]. Nevertheless, the effect of eccentricity needs further evaluation, being a situation which can be commonly found in practice.

Some of the main fire testing programs carried out worldwide have taken the load eccentricity into account (Grandjean et al. [2], Kordina and Klingsch [3], Lie and Chabot [4] or Han et al. [7]), but using only a limited number of column specimens. Also in previous tests from the authors of this paper [10], eccentric loads were used, although the load eccentricity ratio applied was reduced $(e / D=0.13$ and 0.31$)$. Thus, there is a need for investigating the effect of large eccentricities, which can occur in certain type of constructions such as industrial facilities.

Only one fire testing program focusing on slender CFST columns subjected to large eccentricities has been found in the literature, carried out at CTICM [11], where four CFST columns were tested under large eccentricities $(e / D=0.75$ and 1.5$)$, being two of them of circular section and another two of square shape. However, the results of this fire testing program are limited and need to be extended. Therefore, the reduced number of cases found considering large eccentricities motivates the need for carrying out new experimental programs, in order to increase the existing experimental database. 
After a full review of the results of previous tests, an extensive experimental program has been designed in the framework of the European Project FRISCC (Fire resistance of innovative and slender concrete filled tubular composite columns). One of the aims of this project is to provide a full range of experimental evidence on the fire behaviour of CFST columns, a necessary basis for the development of numerical models and simple calculation rules. Four different section shapes are studied in this project: circular, elliptical, square and rectangular hollow section columns filled with concrete, although only the results of the circular and square columns are available at the moment.

The experimental investigation presented in this paper, which is part of the fire testing program being carried out in the mentioned project, focuses on slender CFST columns with circular and square cross-section subjected to large eccentricities. This experimental study will allow understanding the influence of the cross-section shape on the fire performance of CFST columns, as well as the effect of the load eccentricity and percentage of reinforcement.

Another aim of the experimental program presented in this paper is to serve as a basis for the development of safe design rules for the evaluation of the fire resistance of CFST columns. In Europe, different methods are available in Eurocode 4 Part 1.2 [12]. Clause 4.3.5.1 presents a simple calculation model for evaluating the design axial buckling load of composite columns in the fire situation based on the elastic buckling theory. A specific method for columns composed of unprotected concrete filled hollow sections can also be found in Annex $\mathrm{H}$ of the same code. Previous investigations have revealed that this method produces unsafe results for slender columns [13] [14][15], which has led to the approval of an addenda to Eurocode 4 by the committee CEN/TC250/SC4 which limits the applicability of Annex H to columns with slenderness lower than 0.5.

Additionally, the evaluation of the effect of eccentricity by means of the current calculation methods in Eurocode 4 is not clearly solved and needs to be extended to large 
eccentricities, for which further experimental research is needed. Based on the results of the fire tests presented in this paper, the current calculation methods in Eurocode 4 Part 1.2 will be assessed and a new design proposal developed by the authors will be also evaluated for slender columns subjected to large eccentricities.

\section{EXPERIMENTAL INVESTIGATION}

\subsection{General}

Despite a large amount of fire tests can be found in the literature on CFST columns of circular and square section subjected to concentric axial load or moderated eccentricities, it is uncommon to find test results which account for large eccentricities in CFST columns, only Renaud and Kruppa [11] having tested four columns subjected to large eccentricities.

The authors of this paper have performed several experimental campaigns [9][10], to study the fire resistance of slender CFST columns, although further experimental results are needed which include the effect of large eccentricities in slender CFST columns.

The experimental program which is presented in this paper consists of a total of 12 columns, six of them having circular section and the other six with square section. Two different cross-sectional dimensions were used for each shape, and large eccentricities were applied in most of the tests, with load eccentricity ratios $(e / D$ or $e / B)$ of 0.5 and 0.75 . Two of the columns on each group were tested under concentric load, so as to have a reference for evaluating the effect of the load eccentricity. All the columns were bar-reinforced, using reinforcement ratios ranging between $2.4 \%$ and $5.15 \%$. The columns were hinged at both ends, having a length of $3180 \mathrm{~mm}$. The steel tubes had a nominal strength of $355 \mathrm{MPa}$, while the concrete used for filling the columns had a compressive strength of $30 \mathrm{MPa}$. The load level applied to the columns was a $20 \%$ of their load bearing capacity at room temperature, which had been calculated by means of a previously validated numerical model. 
The square columns were designed to have approximately the same steel area as their circular counterparts, in order to be able to compare their effectiveness in the fire situation for the same steel usage.

The tested specimens, with their particular characteristics and resulting fire resistance measured in minutes, are listed in Table 1 (circular columns) and Table 2 (square columns). The cross-sectional dimensions and reinforcement arrangement of the tested columns can be seen in Fig. 1.

\subsection{Test setup}

The fire tests were performed in the facilities of AIDICO (Instituto Tecnológico de la Construcción) in Valencia (Spain), using a $5 \times 3 \mathrm{~m}$ furnace equipped with a hydraulic jack with a maximum capacity of $1000 \mathrm{kN}$ and a total of 16 gas burners, located at mid-height of the furnace chamber. Fig. 2a presents a schematic view of the experimental setup for the concentrically loaded tests, while the preparation of one of the specimens can be seen in Fig. 4a.

The load was applied to the top end of the columns through a knife-edge bearing (Fig. 4c and Fig. 4d), which permitted to introduce the desired eccentricity. The same eccentricity was applied at both column ends. Once the load was applied, it was kept constant while the standard ISO-834 [16] fire curve was prescribed, with unrestrained column elongation.

\subsection{Column specimens}

The length of the columns was $3180 \mathrm{~mm}$, although only $3040 \mathrm{~mm}$ were directly exposed to the fire inside the furnace, as indicated in Fig. 2a.

A $300 \times 300 \times 15 \mathrm{~mm}$ steel plate was welded to the bottom end of the columns. The columns were then put in an upright position and filled with concrete, and afterwards shaken by means of an external vibrator in order to consolidate the concrete inside the steel tube. The 
columns were sealed with plastic at their top ends in order to avoid moisture leaks and left upright for 28 days. After concrete was cured, the top surface of the columns was polished and a second end plate of the same dimensions was then welded to the top end of the columns. For each column specimen, two vent holes of $15 \mathrm{~mm}$ diameter were drilled in the steel hollow section wall at $100 \mathrm{~mm}$ from each column end. These vent holes were provided for relieving the water vapour pressure produced during the experiment. An additional hole, located near the bottom end of the columns, was used for connecting the thermocouple wires.

\subsection{Instrumentation}

In order to register the temperature evolution inside the columns during the fire tests, three layers of six thermocouples each (TC1 to TC6) were placed at different heights, as it can be seen in Fig. 2b. TC1 and TC6 were located at the steel tube exposed surface, with $90^{\circ}$ deviation between them, while the other 4 thermocouples (TC2 to TC5) were embedded in the concrete core.

The temperature inside the furnace chamber was automatically registered and controlled during the tests by means of 6 plate thermocouples and a pressure sensor. The axial elongation at the top end of the columns was measured during the tests by means of a LVDT located outside the furnace.

\subsection{Material properties}

The hollow tubes used in the experimental program had a S355 steel grade, nevertheless the real strength $\left(f_{\mathrm{y}}\right)$ of steel was obtained by performing the corresponding coupon tests, and is summarized in Table 1 and Table 2. Normal strength concrete (30 MPa) was used for the column infill. In order to determine the compressive strength of concrete, sets of concrete cylinders were prepared and cured in standard conditions during 28 days. All cylinder samples were tested on the same day as the column fire test. The cylinder compressive 
strength of all the tested specimens $\left(f_{c}\right)$ can be found in Table 1 and Table 2 . The columns had the reinforcement arrangements shown in Fig. 1 using $6 \mathrm{~mm}$ stirrups with $30 \mathrm{~cm}$ spacing. The corresponding geometrical reinforcement ratios $\left(\rho=A_{\mathrm{s}} / A_{\mathrm{c}}\right)$ and measured yield strength $\left(f_{s}\right)$ are given in Table 1 and Table 2.

In order to measure the concrete moisture content, cubic specimens of $150 \times 150 \times 150$ $\mathrm{mm}$ were also prepared. The moisture content was obtained according to the procedure described in ISO 12570:2000 [17].

\section{ANALYSIS OF RESULTS}

\subsection{Thermal response}

The evolution of temperatures at mid-height section (A-A') for one of the columns tested (specimen C4) can be seen in Fig. 3. The average furnace curve has been compared in this graph with the ISO-834 fire curve, proving that the average gas temperature followed closely the standard fire curve. It can be observed that thermocouples TC1 and TC6, located at the steel tube outer surface (with $90^{\circ}$ deviation), had the same evolution along all the fire exposure and became closer to the furnace curve as the time increased. Therefore, the sectional exposure of the column to the fire can be considered to be uniform. The temperatures measured at the concrete core (TC2-TC5) were significantly lower, being observed a decrease in the heating rate (plateau in the curves) between $100^{\circ} \mathrm{C}$ and $200^{\circ} \mathrm{C}$ due to the heat consumption by water evaporation. Thermocouple TC2, closer to the steelconcrete interface, registered the higher temperatures inside the concrete core, while TC4, located at the center of the section provided the lower measurements. 


\subsection{Mechanical response}

The typical failure mode observed in all the columns was overall buckling, as can be seen in Fig. $4 \mathrm{~b}$ for one of the tested specimens. Fig. 5 and Fig. 6 show the evolution of the axial displacement measured at the top end of the columns versus the fire exposure time for all the tested specimens, grouped according to their section shape (circular or square) and dimensions. The resulting fire resistance time expressed in minutes, obtained according to EN 1363-1 [18] is listed in Table 1 for the circular columns and Table 2 for the square columns.

In those tests performed under concentric load, the axial displacement versus time curve presented four stages, with a contribution of the concrete core after the steel tube yielding, which is reflected as a plateau in this curve. Nevertheless, for the columns subjected to eccentric load, only two stages were observed in the axial displacement versus time curve: axial elongation of the column and sudden failure after the yielding of the steel tube occurred, thus not taking advantage of the contribution of the concrete core, due to the high slenderness of these specimens combined with the application of large eccentricities. See reference [19] for a more detailed description on the different failure modes.

Comparing the circular columns with their square counterparts, which made use of the same quantity of steel, the fire response of the circular columns resulted more efficient. This can be seen more clearly in Fig. 7 by comparing cases C1-S1 and C5-S5, where for the same fire resistance time, the circular columns sustained higher loads (with increments of $15.8 \%$ and $14.4 \%$, respectively), or more clearly comparing cases C4-S4, where the circular column showed a $33.3 \%$ higher fire resistance time for the same load applied. Therefore, it can be concluded that, for the same steel usage, the circular columns present a better fire behaviour than the square columns. It is worth noting that the slenderness values of the square columns were higher in all cases (see Fig. 7d). It is also important to note that the section factor $\left(A_{m} / V\right)$ 
of the circular columns was lower than that of the square columns, which made them perform better in the fire situation, as they exposed a lower surface to the fire for the same volume.

The effect of the load eccentricity can be also seen in Fig. 5 and Fig. 6. If cases S2 and S4 are compared, it can be seen that for the same column dimensions and percentage of reinforcement, the fire resistance time was significantly reduced when applying the eccentricity (23 $\mathrm{min}$ ), in comparison to the concentrically loaded test (54 min), having the second case twice the load applied to the first case (see Fig. 7c). If the percentage of reinforcement is increased from $2.5 \%$ to $5 \%$, with the same load eccentricity applied (S6 versus S2), the fire resistance time increases (29 min versus $23 \mathrm{~min}$ ), even when the applied load is also higher. Therefore, this result confirms that the reinforcement contributes slightly to improve the fire resistance of these columns, although it does not provide a definitive solution to the reduced fire endurance of slender columns, for which alternative solutions such as using external protection or tube-in-tube systems should be considered.

\section{STUDY AND DISCUSSION OF EUROCODE 4}

In this section, the test results are compared with the design rules in Eurocode 4 Part 1.2 [12]. Two different approaches are given in this standard: the simple calculation model for composite columns in Clause 4.3.5.1 and a specific method for unprotected concrete filled hollow sections in Annex H.

Clause 4.3.5.1 presents a method for calculating the design value of the buckling resistance of columns subjected to concentric axial loads in the fire situation, based on the elastic buckling theory. In turn, Annex $\mathrm{H}$ presents an iterative method which results particularly difficult to implement for fire design, as it requires the systematic evaluation of the stress at the different layers by means of the material non-linear stress-strain relationships at elevated temperatures, increasing the strain in steps until the equilibrium between the critical buckling load and the design value of the plastic resistance is found. 
The method in Annex $\mathrm{H}$ has been assessed in different papers [13][14][20] and research projects [11], which have revealed that this method results inaccurate for the evaluation of the fire resistance of CFST columns. As a consequence, a number of countries (e.g. United Kingdom [21]) have already included in their National Annexes the prohibition to use of this method. Alternatively, it is suggested to use the general method in Clause 4.3.5.1, where a series of assumptions need to be adopted for the application of this method to CFST columns.

As part of the method, the effective flexural stiffness of the columns in the fire situation needs to be calculated, being defined in Clause 4.3.5.1(5) as:

$$
(E I)_{f i, e f f}=\sum_{j}\left(\varphi_{a, \theta} E_{a, \theta} I_{a, \theta}\right)+\sum_{k}\left(\varphi_{s, \theta} E_{s, \theta} I_{s, \theta}\right)+\sum_{m}\left(\varphi_{c, \theta} E_{c, \text { sec }, \theta} I_{c, \theta}\right)
$$

The evaluation of this equation requires the definition of a set of reduction coefficients $\left(\varphi_{i, \theta)}\right.$ to account for the effect of the thermal stresses. Nevertheless, the values of these coefficients are not specified in the code for CFST columns. In the absence of these values, different assumptions have been suggested in the design guidance, as to take them as equal to unity or to use the values in Annex G for partially encased steel sections [20][22].

\subsection{Load eccentricity}

The previous methods are valid for evaluating the axial capacity of concentrically loaded columns. For taking into account the load eccentricity in the case of CFST columns, reference is made in Clause 4.3.5.3 to Section H.4 in Annex H. Two correction coefficients are given in Figures H.1 and H.2 of Annex H: $\varphi_{s}$, which is a function of the percentage of reinforcement, and $\varphi \delta$, which is a function of the eccentricity and the slenderness of the column.

$N_{f i, R d, \delta}=N_{f i, R d} \cdot \varphi_{s} \cdot \varphi_{\delta}$

On a first instance, the buckling resistance of the column under concentric axial load $N_{f i, R d}$ is calculated and, afterwards, it is corrected by means of the two coefficients $\varphi_{s}$ and $\varphi_{\delta}$, 
for obtaining the corresponding buckling load that the column can attain with the given eccentricity $N_{f i, R d, \delta}$. These graphs have been included in Fig. 8 for a better understanding.

It is worth noting that Figure H.2 of Annex H for the correction coefficient $\varphi_{\delta}$ does only reach a relative eccentricity of 0.5 , while in this experimental program two of the columns (C5 and S5) have a relative eccentricity of 0.75 applied. In the absence of values of the correction coefficient for these particular cases, the graph has been extrapolated (see Fig. 8b), although this coefficient should be calibrated in the future to allow for large eccentricities.

A different approach can be found in Section G.7 of Annex G, for composite columns with partially encased steel sections. In that case, the design fire buckling load with eccentricity $N_{f i, R d, \delta}$ is calculated from the concentric axial buckling load in the fire situation $N_{f i, R d}$ corrected by means of the relation between these two loads at room temperature.

$$
N_{f i, R d, \delta}=N_{f i, R d}\left(N_{R d, \delta} / N_{R d}\right)
$$

\subsection{Application of Eurocode 4 to the tested columns}

The previously described methods are assessed by comparing their predictions with the test results from the experimental program presented in Section 2.

The application of these methods requires the previous calculation of the temperature field of the composite cross-section after a given duration of fire exposure. For obtaining the temperature field at the time of test failure, the column cross-section is subdivided into a number of concentric layers of the same thickness, using a maximum thickness of $20 \mathrm{~mm}$ in order to obtain a realistic approximation. The temperatures at the different layers are obtained by using linear interpolation from the measured temperatures at the locations of the thermocouples.

Once the temperature field at the time of failure is known, the design axial buckling load $N_{f i, R d}$ is calculated for that distribution of temperatures, applying either the method in 
Annex $\mathrm{H}$ or the general model from Clause 4.3.5.1. In the second case, two different approaches have been used for evaluating the effective flexural stiffness given in eq. (1). In the first approach, a value equal to unity has been given to the reduction coefficients $\varphi_{i, \theta}$, which is equivalent to neglect the effect of thermal stresses. In the second approach, the values of these reduction coefficients have been taken from Table G.7 in Annex G (partially encased composite sections), as suggested in the British "Design Guide for Concrete Filled Hot Finished SHS Columns" [21]. A constant value $\varphi_{c, \theta}=0.8$ is given to the concrete core, while for the steel tube and reinforcing bars, these values depend on the fire rating as given next:

- Fire rating R30 and R120: $\varphi_{a, \theta}=\varphi_{s, \theta}=1$

- Fire rating R60: $\varphi_{a, \theta}=\varphi_{s, \theta}=0.9$

- Fire rating R90: $\varphi_{a, \theta}=\varphi_{s, \theta}=0.8$

The predictions obtained by means of the applied methods are summarized in Table 3 for the circular columns and Table 4 for the square columns. In these tables, the prediction errors have been computed as the test load divided by the calculated load.

For the eccentrically loaded columns, the calculated buckling load has been corrected by means of two different options: a) using the correction coefficients from Section H.4 in Annex $\mathrm{H}$ (eq. 2), b) using the relation between the eccentric capacity and axial capacity at room temperature, as given in Section G.7 of Annex G (eq. 3). Table 3a and Table 4a present the results with the first option, while Table $3 \mathrm{~b}$ and Table $4 \mathrm{~b}$ provide the results using the second option. A comparison between the calculated buckling loads and the test loads can be also seen graphically in Fig. 9 for the circular columns and Fig. 10 for the square columns, having been considered in both figures option a) for taking the eccentricity into account.

As it can be seen, the method in Annex H produced unsafe results for all the columns, with an average value of the error equal to 0.61 for the circular columns and 0.58 for the 
square columns. The simple calculation model in Clause 4.3.5.1 results also unsafe with an average error of 0.71 for the circular columns and 0.75 for the square columns when using unity coefficients. When the coefficients from Annex G are applied, the predicted loads still lead to unsafe results, with average error 0.76 for the circular columns and 0.79 for the square columns.

Comparing the results of the axially loaded columns (C3, C4 and S3, S4) with the eccentrically loaded columns $(\mathrm{C} 1, \mathrm{C} 2, \mathrm{C} 5, \mathrm{C} 6$ and $\mathrm{S} 1, \mathrm{~S} 2, \mathrm{~S} 5, \mathrm{~S} 6)$, similar results were obtained, with unsafe predictions under both calculation methods. For the eccentrically loaded columns, comparable results were obtained when correcting the axial load by means of eq. (3), with similar average errors and dispersion (see values of mean and standard deviation).

As was obtained by the authors in previous investigations, these results confirm that both Annex $\mathrm{H}$ and the general method in Clause 4.3.5.1 produce unsafe results for concentrically loaded slender columns [14][15]. Depending on the values used for the flexural stiffness reduction coefficients $\left(\varphi_{i, \theta)}\right.$, the results become closer to the experimental loads, which suggests that the calculation method in the main body of Eurocode 4 could be safely applied provided that an appropriate set of reduction coefficients were developed.

For eccentrically loaded columns, the results obtained in this paper seem not to be in line with the findings from previous papers of the same authors [10], where safe although excessively conservative predictions had been obtained for some of the cases analyzed. However, this difference is due to the correction coefficient $\varphi_{s}$ from Figure H.1 (see Fig. 8a), which highly penalizes the values of the calculated buckling load for unreinforced columns $\left(\varphi_{s}=0.4\right)$, while for the columns analyzed in this paper (all of them reinforced with $\rho$ varying between $2.4 \%$ and $5.15 \%) \varphi_{s}$ ranges between 0.87 and 0.95 , being much higher and therefore introducing less conservativeness in the predictions. In the previous paper from the authors [10] it was observed that, while for unreinforced columns the application of these correction 
coefficients produced excessively safe-sided results, for reinforced columns more realistic results were obtained, although sometimes overestimating the load. This is now confirmed with the reinforced columns from this paper, where for large eccentricities unsafe results have been obtained. Therefore, it is suggested that appropriate correction coefficients are developed to account for the effect of the eccentricity when applying the simple calculation model from Eurocode 4.

\subsection{Design proposal}

The tests results are also compared in this section with the design proposal presented by the authors in previous papers [14][15]. This method is based on the simple calculation model in Clause 4.3.5.1 from Eurocode 4 Part 1.2, completing it with a new proposal of flexural stiffness reduction coefficients $\left(\varphi_{i, \theta}\right)$ and buckling curves. The method is valid for concentrically loaded columns with circular and elliptical cross-section, but it will also be assessed for square columns by comparing with the available test results. For the case of eccentric loads, as a specific method has not yet been developed, the same two options used in the previous section for correcting the calculated axial load will be used: a) correction coefficients from Section H.4 in Annex H (eq. 2), b) correction by means of the relation between the eccentric capacity and axial capacity at room temperature, as given in Section G.7 of Annex G (eq. 3).

In this previous design proposal, a specific formulation was developed for obtaining the values of the flexural stiffness reduction coefficients $\left(\varphi_{i, \theta}\right)$ to use in equation (1). For the concrete core, a constant value equal to $\varphi_{c, \theta}=0.8$ was proposed, used in combination with the initial tangent stiffness. Note that Eurocode 4 defines the concrete stiffness in fire design using the secant modulus for the peak of the stress-strain curve. The tangent modulus in origin is 1.5 times the secant modulus, therefore $\varphi_{c, \theta}=0.8 \times 1.5=1.2$ if the secant modulus is used. 
For the steel tube, a specific equation for evaluating the reduction coefficient was proposed by Espinos et al. [14]:

$$
\varphi_{a, \theta}=\varphi_{a, \theta 1}(D / t) \times\left(2.747-1.48 \cdot\left(A_{m} / V\right)^{0.08}\right) \times\left(0.0813+0.0133 \cdot\left(\ell_{\theta} / D\right)^{1.097}\right) \leq 1
$$

In this equation, the reduction coefficient $\varphi_{a, \theta}$ is a product of two partial reduction coefficients lower than unity, $\varphi_{a, \theta_{2}}$ and $\varphi_{a, \theta 3}$, which must be corrected by the factor $\varphi_{a, \theta_{1}}$ as a function of $D / t$ only for stocky columns $\left(\ell_{\theta} / D \leq 12\right)$, using the values given in [14]. For $\ell_{\theta} / D>12$, the factor $\varphi_{a, \theta l}$ is equal to unity. For evaluating this expression in the case of square columns, the diameter is replaced by the width of the section $(B)$.

For bar-reinforced columns, the reduction coefficient of the reinforcing bars $\left(\varphi_{s, \theta}\right)$ and the corresponding buckling curve can be obtained from Espinos et al. [15], as a function of the percentage of reinforcement. If the percentage of reinforcement is lower than $2.5 \%$, a reduction coefficient $\varphi_{s, \theta}=0.6$ is applied to the reinforcing bars and buckling curve "b" is used, while for higher values of the percentage of reinforcement $\varphi_{s, \theta}=0.3$ and buckling curve "c" is selected.

For applying the proposed method, the temperature field obtained from the experiments has been used, where the representative temperatures of the different layers in which the cross-section is subdivided are interpolated from the measurements at the location of the thermocouples. The results of the application of the proposed method have been included in Table 3 and Table 4.

A comparison between the predicted buckling loads and the test loads can be also seen graphically in Fig. 9 for the circular columns and Fig. 10 for the square columns, where these results have been superimposed with those obtained previously with the methods in Eurocode 4 Part 1.2. 
As it can be seen, the proposed method produced more accurate and conservative predictions, with an average error equal to 1.02 for the circular columns and 1.10 for the square columns. This result confirms that the proposed method can be safely applied to axially and eccentrically loaded columns (even with large eccentricities) and is also applicable to square columns producing similar results. For the eccentrically loaded columns, comparable results were obtained using the correction from eq. (3), with an average error of 1.05 for the circular columns and 1.04 for the square columns and a similar dispersion.

In order to improve the accuracy of the proposed method and extend its validity to eccentrically loaded columns, it is needed that specific correction coefficients to take into account the effect of the load eccentricity and percentage of reinforcement are developed based on parametric studies, which will be carried out within the framework of the European project FRISCC.

\section{SUMMARY AND CONCLUSIONS}

The results of an experimental program on slender CFST columns of different crosssection shapes subjected to large eccentricities have been presented in this paper. A total of six circular columns and six square columns were tested under pinned end conditions and subjected to a $20 \%$ load level, being exposed to the standard ISO-834 fire curve. The test parameters investigated in this experimental program were the cross-section shape, sectional dimensions, member slenderness, load eccentricity and reinforcement ratio. From the results of the fire tests, it was found that, for the same steel usage, the circular columns presented a better fire performance than the square columns. Additionally, for the same column dimensions and percentage of reinforcement, the fire resistance time was significantly reduced when introducing eccentricity. Furthermore, it was found that for the same load eccentricity, when the percentage of reinforcement was increased, the fire resistance time also increased. 
On the basis of the tests results, the current provisions in Eurocode 4 Part 1.2 were assessed, as well as the calculation method proposed by the authors in previous investigations. It was found that, both the simple calculation model in Clause 4.3.5.1 and the method in Annex $\mathrm{H}$ - which use is not permitted in some European countries - lead to unsafe predictions for both axially and eccentrically loaded columns. Several options were studied for taking into account the eccentricity of the load (Section H.4 or Section G.7 in Eurocode 4 Part 1.2), producing similar results. Also different options were considered for taking into account the effect of thermal stresses in the evaluation of the flexural stiffness at elevated temperatures, producing unsafe results. It was found that, depending on the values used for the flexural stiffness reduction coefficients, the results became closer to the experimental loads, which suggests that these coefficients should be revised on the basis of experimental results, in order to safely apply the simple calculation model in Clause 4.3.5.1. It has been proved that the method proposed by the authors - which completes the simple calculation model with a new proposal of coefficients and buckling curves - provides safe predictions of the buckling loads and can be used for both geometries (circular and square) and in combination with the correction coefficients in Section H.4 to account for the load eccentricity, or alternatively using a correction based on the relation of ultimate loads at room temperature as given in Section G.7. Nevertheless, there is a need to develop specific correction coefficients to improve the accuracy of the method for eccentrically loaded columns, which will be done in the future on the basis of the parametric studies to be carried out within the European Project FRISCC.

Additionally, the proposed method should be extended to other cross-section shapes such as rectangular or elliptical sections, which will be one of the future tasks to carry out in the aforementioned project. 
It should be noted that the conclusions drawn in this paper are valid for columns with moderated section sizes (circular columns with 193.7-273 mm diameter, square columns with 150-220 mm width) and high member slenderness (0.54-0.94). In future parametric studies, wider sections will be studied in order to analyze how the size effect can influence these conclusions. Also the effect of using different eccentricities at both column ends will be addressed in the future through parametric studies.

\section{ACKNOWLEDGEMENTS}

The authors would like to express their sincere gratitude to the European Union for the help provided through the Project RFSR-CT-2012-00025, carried out with a financial grant of the Research Programme of the Research Fund for Coal and Steel.

\section{REFERENCES}

[1] COMETUBE. Fire resistance of structural hollow sections. Cometube research. CIDECT programme 15A. Final report; 1976.

[2] Grandjean G, Grimault JP, Petit L. Determination de la duree au feu des profils creux remplis de beton. CIDECT Research Project 15B-80/10. Cologne, Germany: Comité International pour le Développement et l'Etude de la Construction Tubulaire; 1980.

[3] Kordina K, Klingsch W. Fire resistance of composite columns of concrete filled hollow sections. CIDECT Research Project 15C1/C2-83/27. Cologne, Germany: Comité International pour le Développement et l'Etude de la Construction Tubulaire; 1983.

[4] Lie TT, Chabot M. Experimental studies on the fire resistance of hollow steel columns filled with plain concrete. Internal report No. 611. Ottawa, Canada: Institute for Research in Construction, National Research Council of Canada (NRCC); 1992. 
[5] Chabot M, Lie TT. Experimental studies on the fire resistance of hollow steel columns filled with bar-reinforced concrete. Internal report No. 628. Ottawa, Canada: Institute for Research in Construction, National Research Council of Canada (NRCC); 1992.

[6] Kodur VKR, Lie TT. Experimental studies on the fire resistance of circular hollow steel columns filled with steel-fibre-reinforced concrete. Internal report No. 691. Ottawa, Canada: Institute for Research in Construction, National Research Council of Canada; 1995.

[7] Han LH, Zhao XL, Yang YF, Feng JB. Experimental study and calculation of fire resistance of concrete-filled hollow steel columns. Journal of Structural Engineering (ASCE) 2003; 129(3):346-356.

[8] Kim DK, Choi SM, Kim JH, Chung KS, Park SH. Experimental study on fire resistance of concrete-filled steel tube column under constant axial loads. International Journal of Steel Structures 2005; 5(4):305-313.

[9] Romero ML, Moliner V, Espinos A, Ibañez C, Hospitaler A. Fire behavior of axially loaded slender high strength concrete-filled tubular columns. Journal of Constructional Steel Research 2011; 67(12):1953-1965.

[10] Moliner V, Espinos A, Romero ML, Hospitaler A. Fire behavior of eccentrically loaded slender high strength concrete-filled tubular columns. Journal of Constructional Steel Research 2013; 83:137-146.

[11] Renaud C, Kruppa J. Unprotected concrete filled columns fire tests - Verification of 15Q. CIDECT Research Project 15R. Saint-Rémy-lès-Chevreuse, France: Centre Technique Industriel de la Construction Métallique (CTICM); 2004.

[12] CEN. EN 1994-1-2, Eurocode 4: Design of composite steel and concrete structures. Part 1-2: General rules - Structural fire design. Brussels, Belgium: Comité Européen de Normalisation; 2005. 
[13] Aribert JM, Renaud C, Zhao B. Simplified fire design for composite hollow-section columns. Structures \& Buildings 2008; 161:325-336.

[14] Espinos A, Romero ML, Hospitaler A. Simple calculation model for evaluating the fire resistance of unreinforced concrete filled tubular columns. Engineering Structures 2012; 42:231-244.

[15] Espinos A, Romero ML, Hospitaler A. Fire design method for bar-reinforced circular and elliptical concrete filled tubular columns. Engineering Structures 2013; 56:384-395.

[16] ISO 834: Fire resistance tests, elements of building construction. Switzerland: International Standards Organisation; 1980.

[17] ISO 12570:2000. Hygrothermal performance of building materials and products Determination of moisture content by drying at elevated temperature.

[18] CEN. EN 1363-1, Fire resistance tests. Part 1: General requirements. Brussels, Belgium: Comité Européen de Normalisation; 1999.

[19] Espinos A, Romero M, Hospitaler A. Advanced model for predicting the fire response of concrete filled tubular columns. Journal of Constructional Steel Research 2010; 66(89):1030-1046.

[20] Leskela MV. Inconsistencies in the fire design rules of composite columns to EN 1994-12. Steel Concrete Composite and Hybrid Structures, pp. 489-494. Leeds, England; 2009.

[21] Wang YC. Design guide for concrete filled hot finished structural hollow section (SHS) columns. TATA Steel; 2014.

[22] Lennon T, Moore DB, Wang YC, Bailey CG. Designers' guide to EN 1991-1-2, EN 1992-1-2, EN 1993-1-2 and EN 1994-1-2. Thomas Telford Limited; 2007. 
Espinos A, Romero ML, Serra E, Hospitaler A. Circular and square slender concrete-filled tubular columns under large eccentricities and fire. J Constr Steel Res. 2015;110:90-100. doi: 10.1016/j.jcsr.2015.03.011

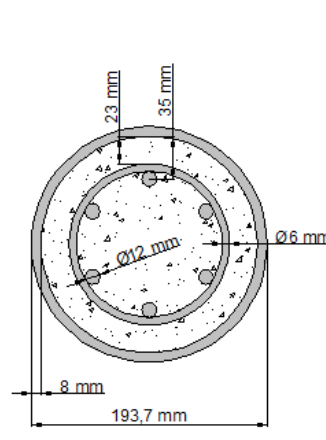

$\mathrm{C} 1 \& \mathrm{C} 3$

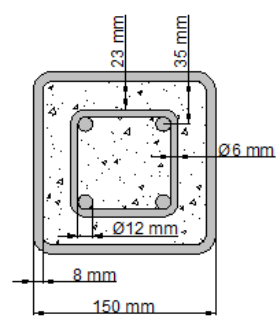

$\mathrm{S} 1 \& \mathrm{~S} 3$

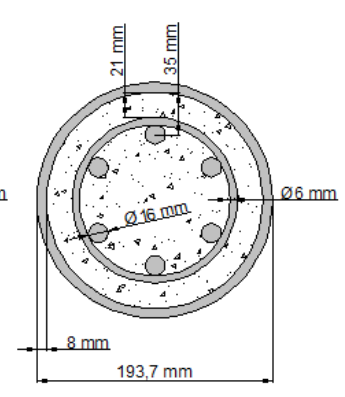

C5

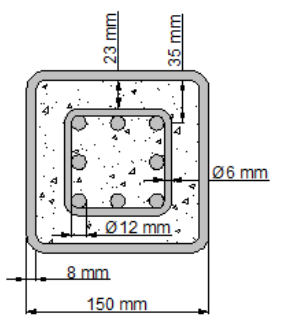

S5

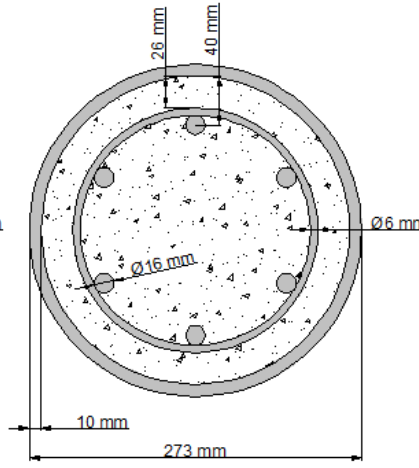

$\mathrm{C} 2 \& \mathrm{C} 4$

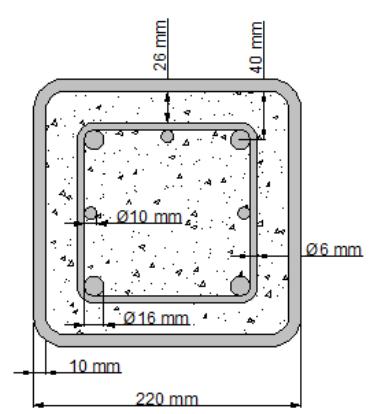

$\mathrm{S} 2 \& \mathrm{~S} 4$

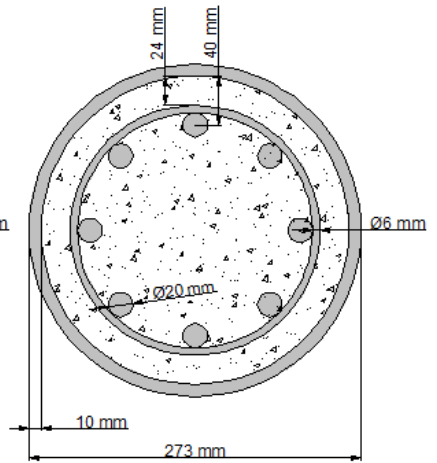

C6

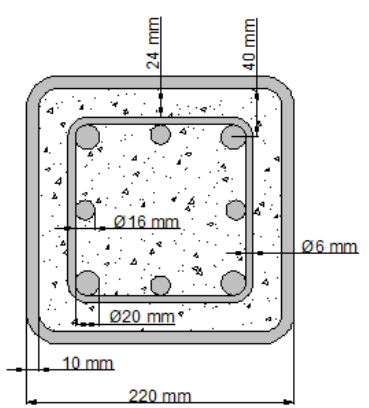

S6

Fig. 1. Cross-sectional dimensions and reinforcement arrangement of the tested columns 
Espinos A, Romero ML, Serra E, Hospitaler A. Circular and square slender concrete-filled tubular columns under large eccentricities and fire. J Constr Steel Res. 2015;110:90-100. doi: 10.1016/j.jcsr.2015.03.011

a)

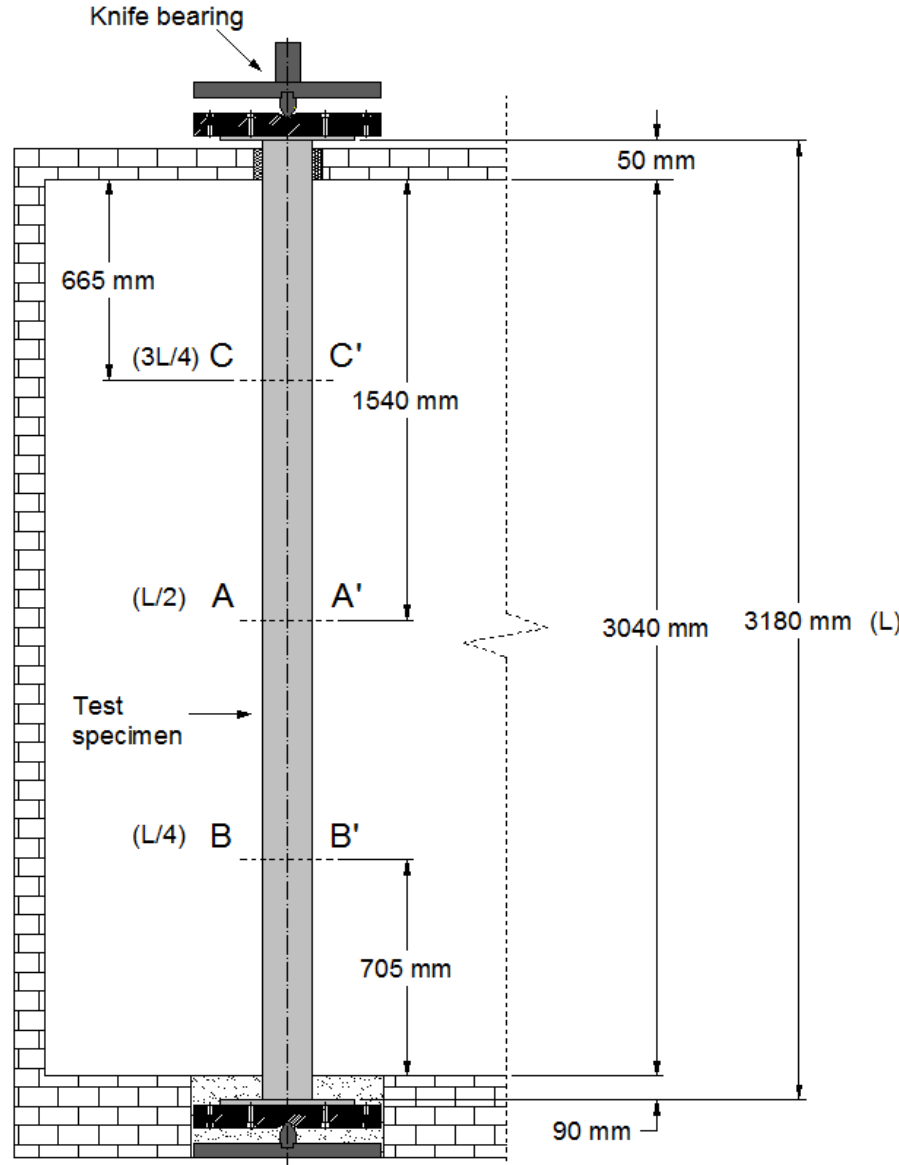

b)

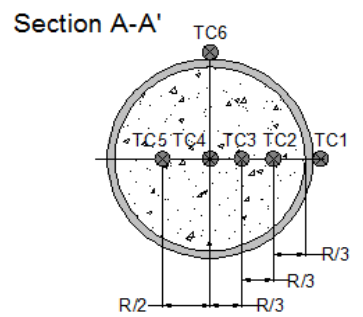

Section B-B'

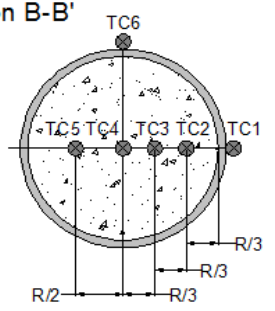

Section C-C'

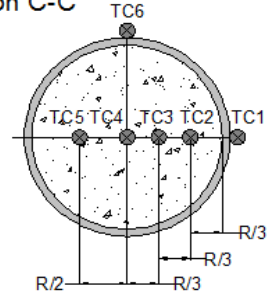

Fig. 2. a) Schematic view of the column inside the furnace; b) thermocouple locations (circular columns) 
Espinos A, Romero ML, Serra E, Hospitaler A. Circular and square slender concrete-filled tubular columns under large eccentricities and fire. J Constr Steel Res. 2015;110:90-100. doi: 10.1016/j.jcsr.2015.03.011

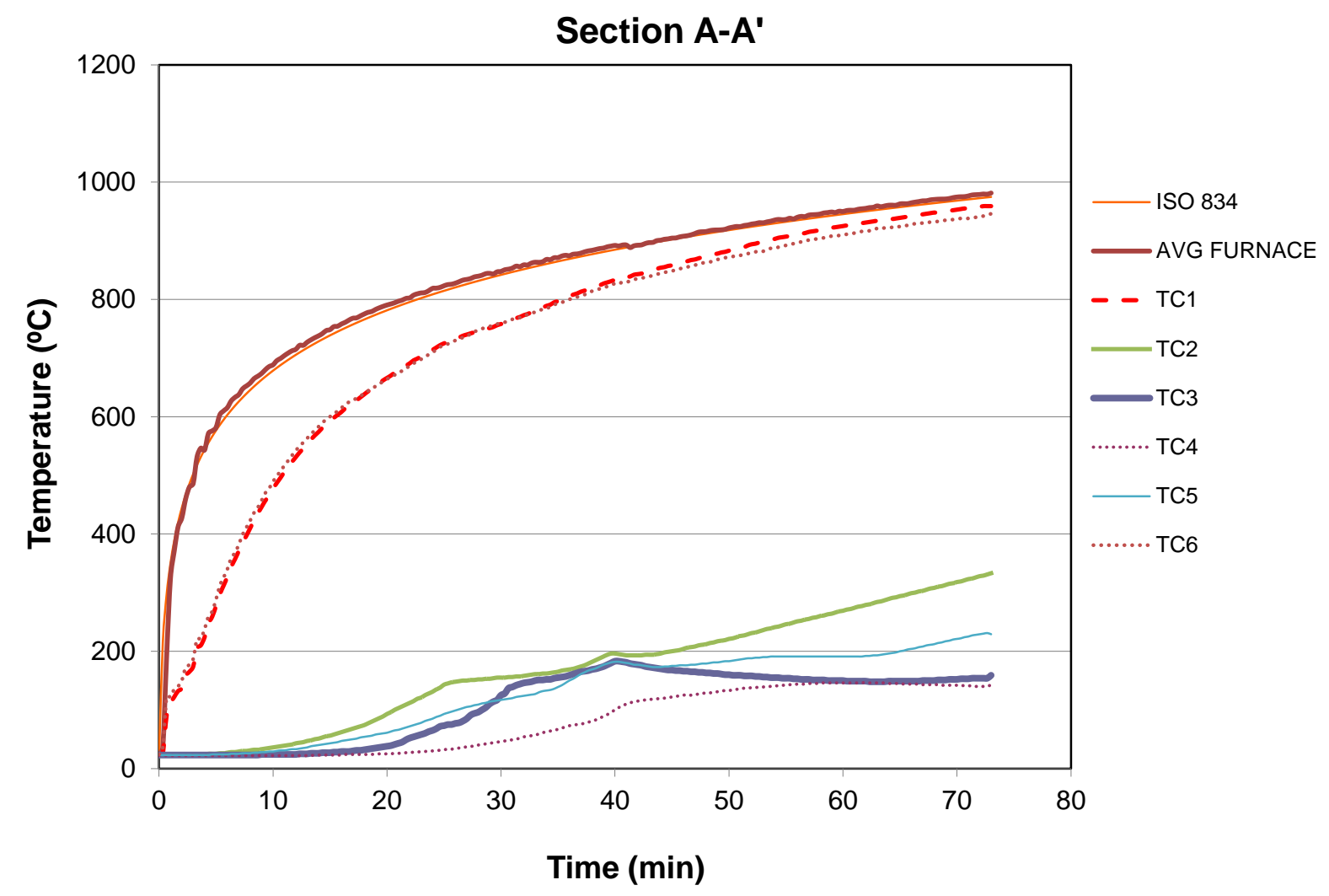

Fig. 3. Evolution of temperatures at mid-height section (A-A'), for column C4. 
Espinos A, Romero ML, Serra E, Hospitaler A. Circular and square slender concrete-filled tubular columns under large eccentricities and fire. J Constr Steel Res. 2015;110:90-100. doi: 10.1016/j.jcsr.2015.03.011
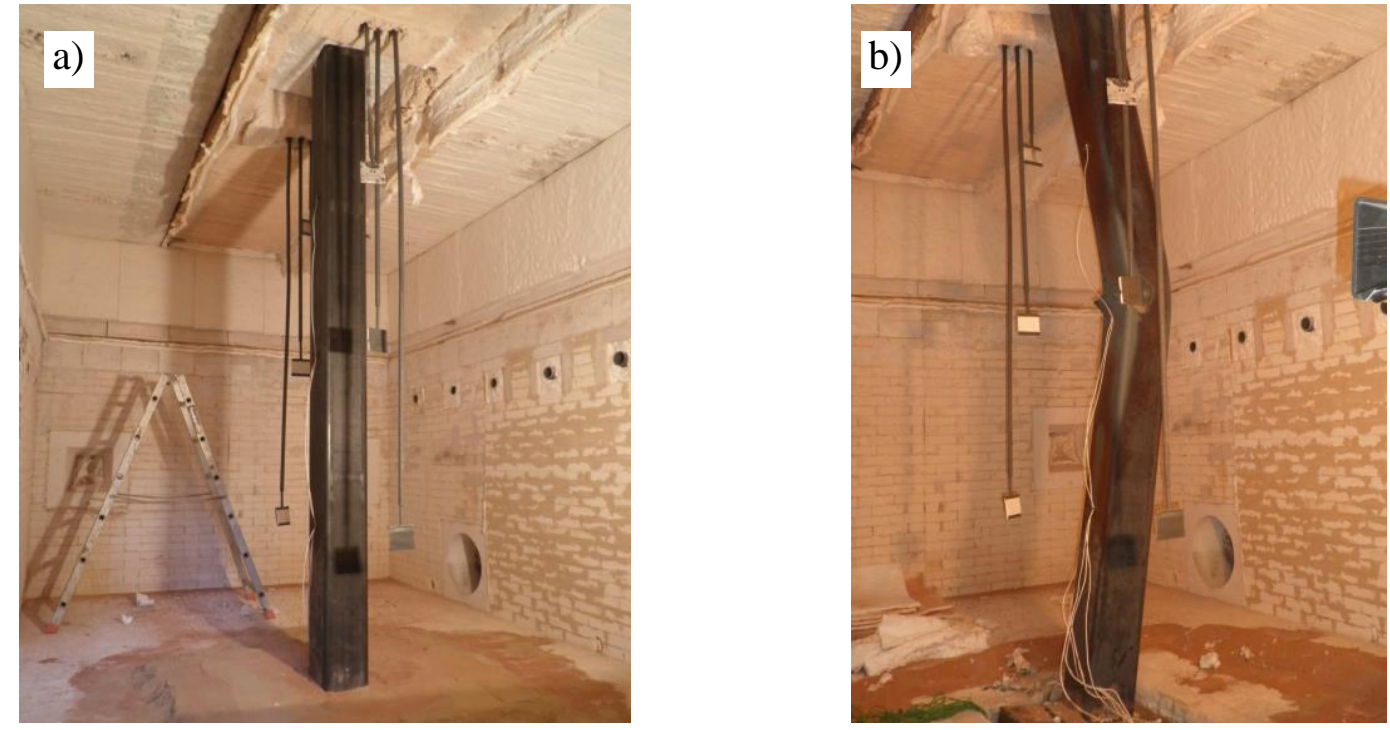

c)
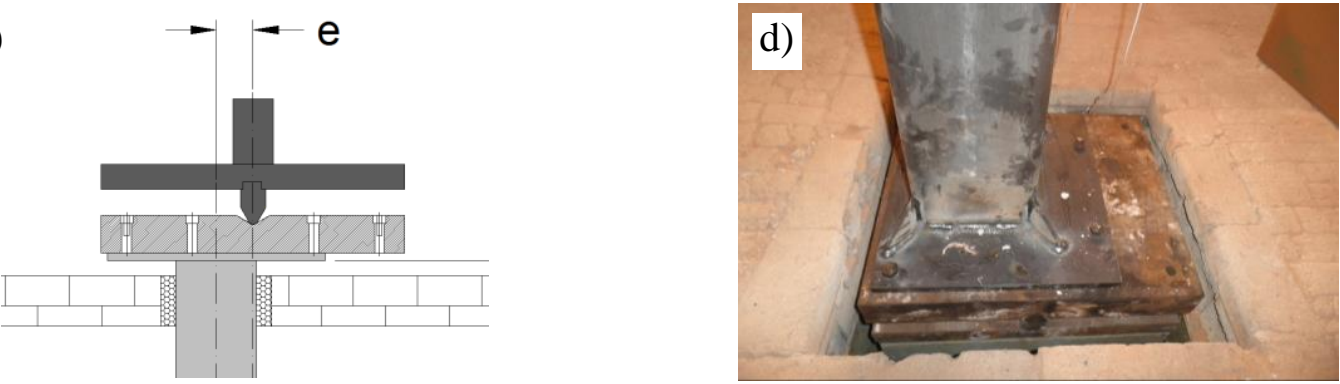

Fig. 4. Square column fire test: a) preparation of the column specimen; b) column after test; c) schematic view of the knife-edge; d) detail of the eccentricity at the bottom end of the column 
a)

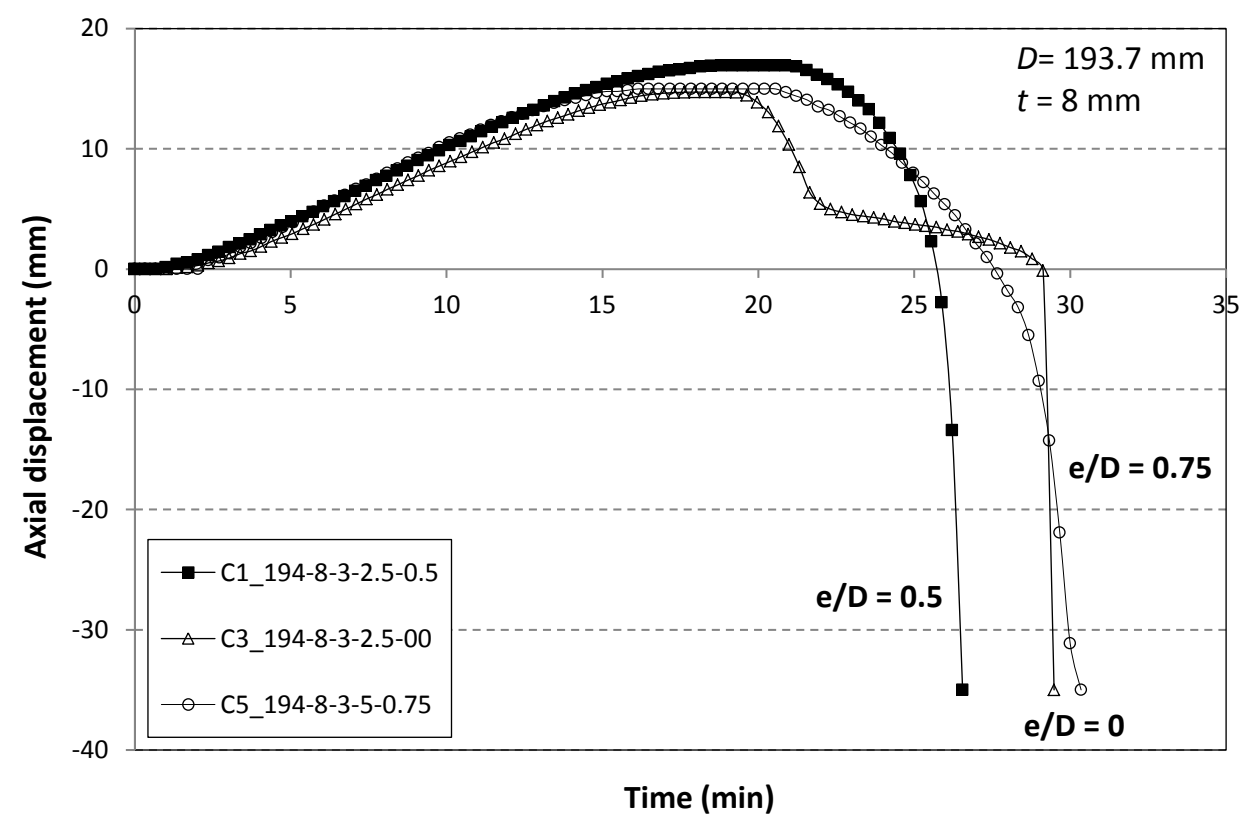

b)

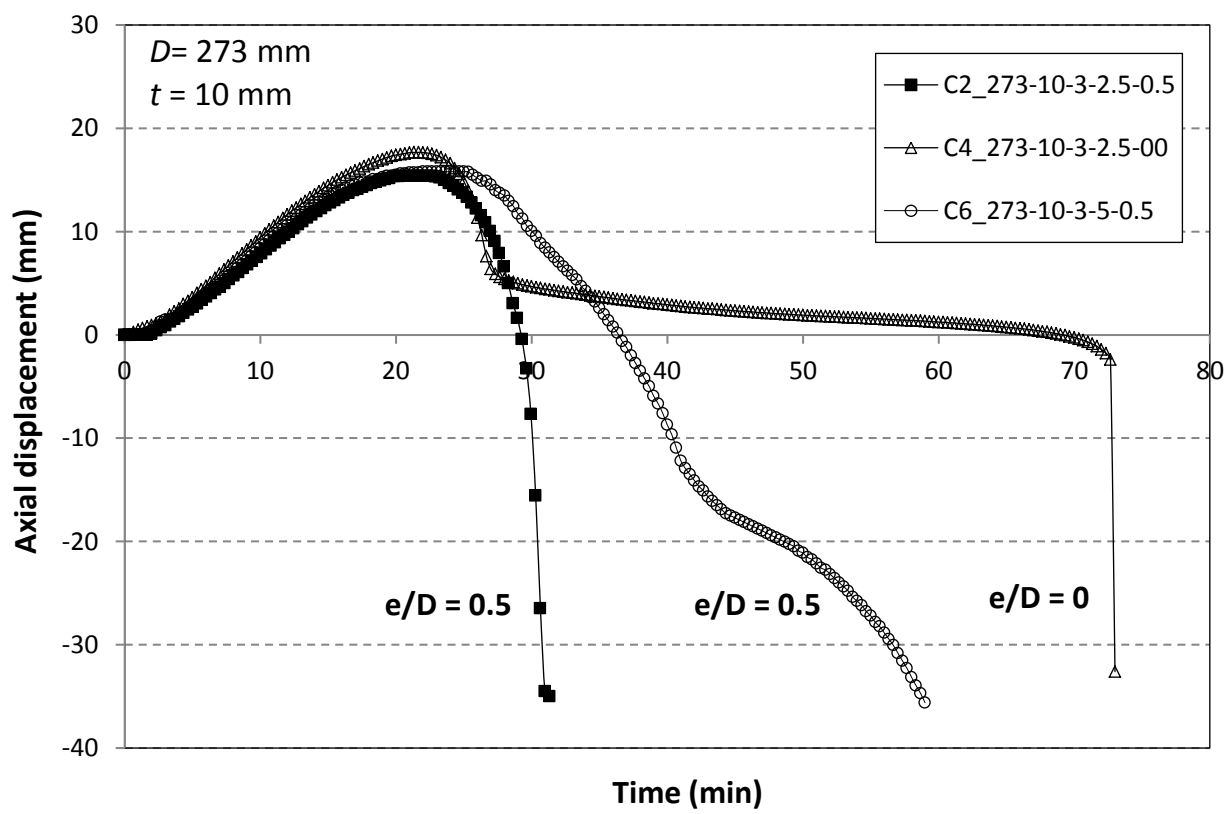

Fig. 5. Results of the fire tests on circular columns: a) CHS $193.7 \times 8 \mathrm{~mm}$; b) CHS $273 \times 10$ $\mathrm{mm}$ 
a)

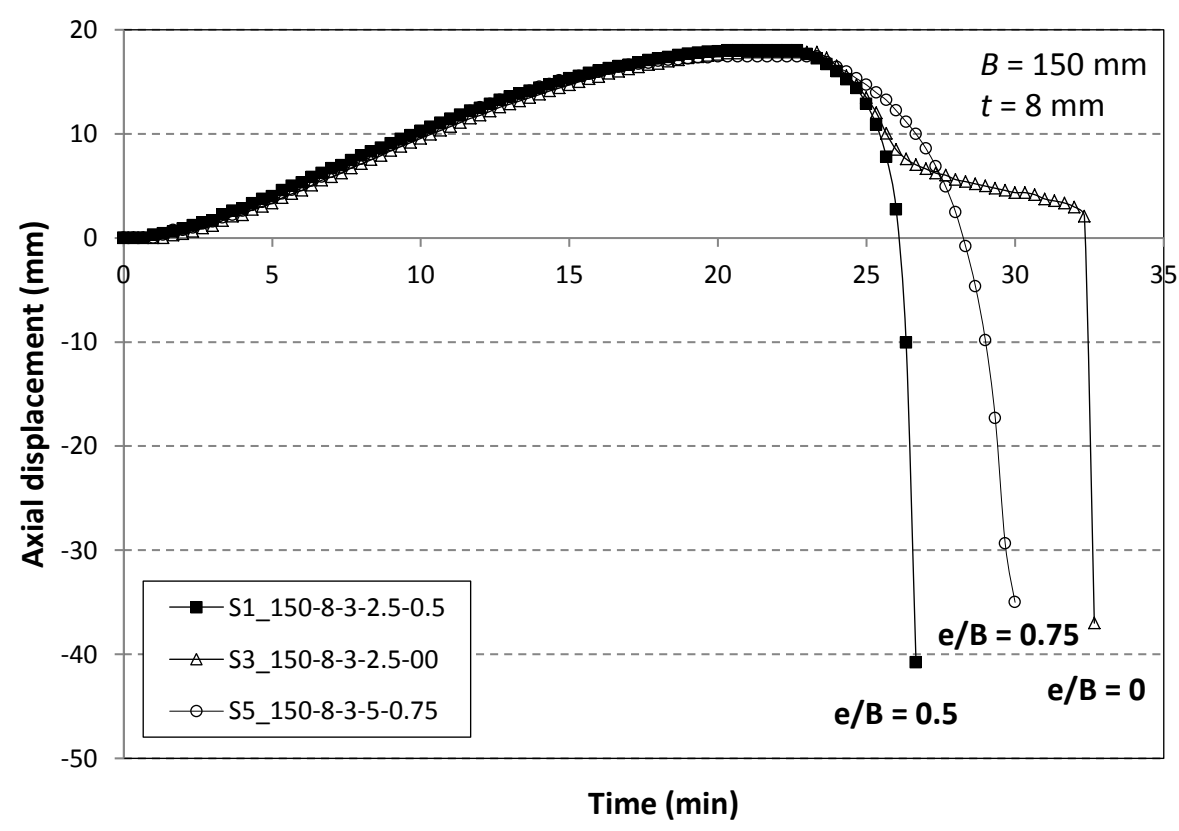

b)

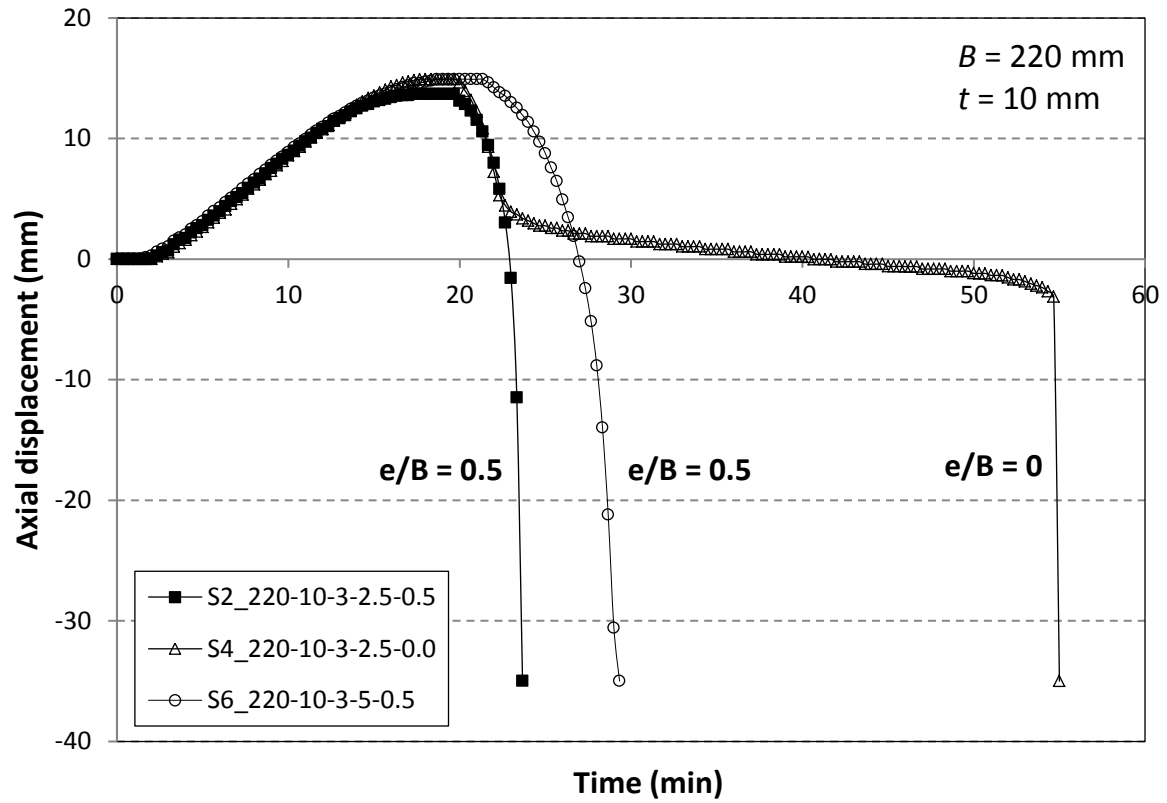

Fig. 6. Results of the fire tests on square columns: a) SHS 150×8 mm; b) SHS $220 \times 10 \mathrm{~mm}$ 
a)

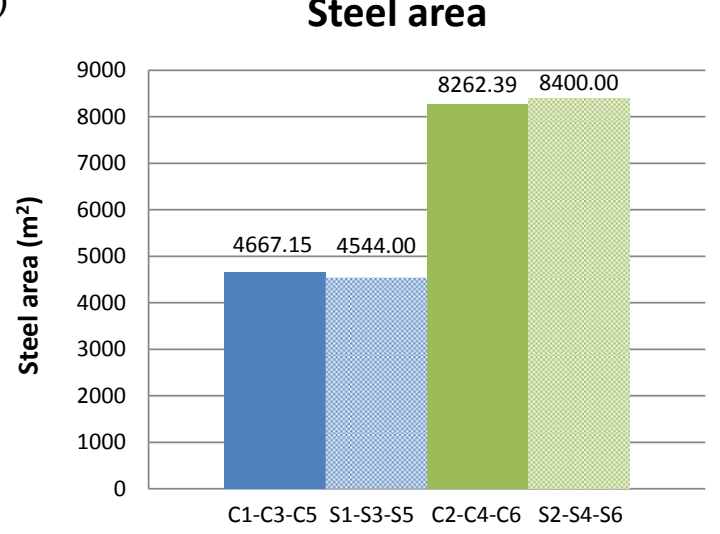

c)

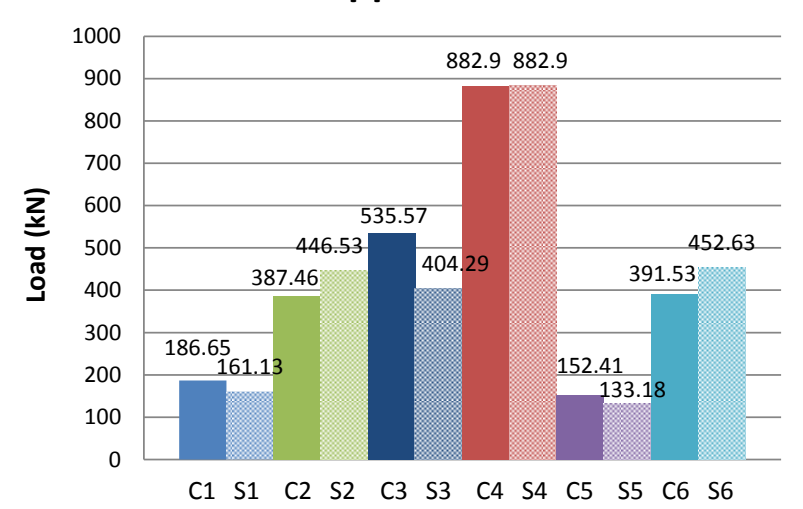

b)

Fire resistance

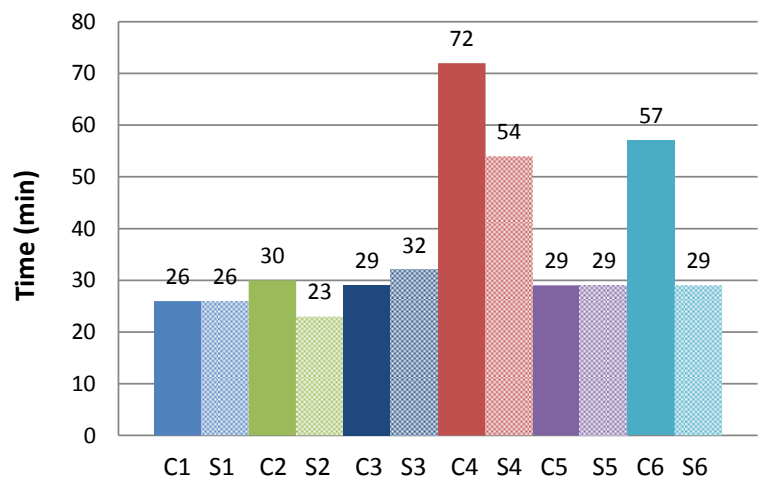

d)

Member slenderness

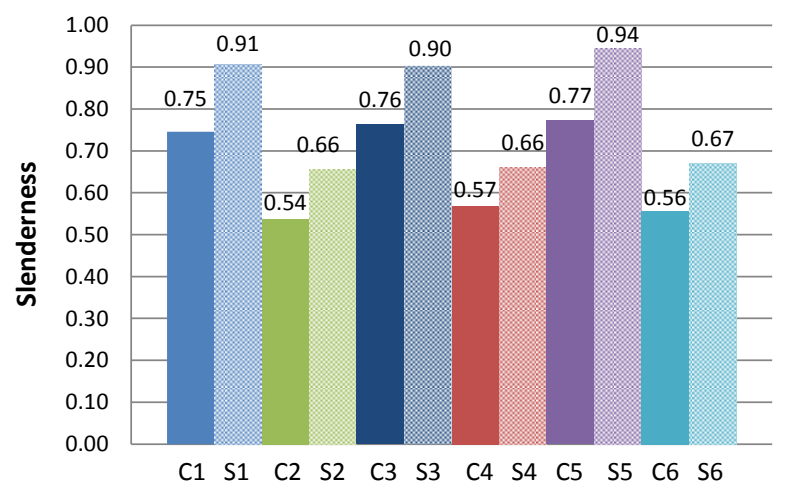

Fig. 7. Comparison between the different circular and square columns tested: a) Steel area; b) Fire resistance time; c) Applied load; d) Member slenderness 
Espinos A, Romero ML, Serra E, Hospitaler A. Circular and square slender concrete-filled tubular columns under large eccentricities and fire. J Constr Steel Res. 2015;110:90-100. doi: 10.1016/j.jcsr.2015.03.011

a)

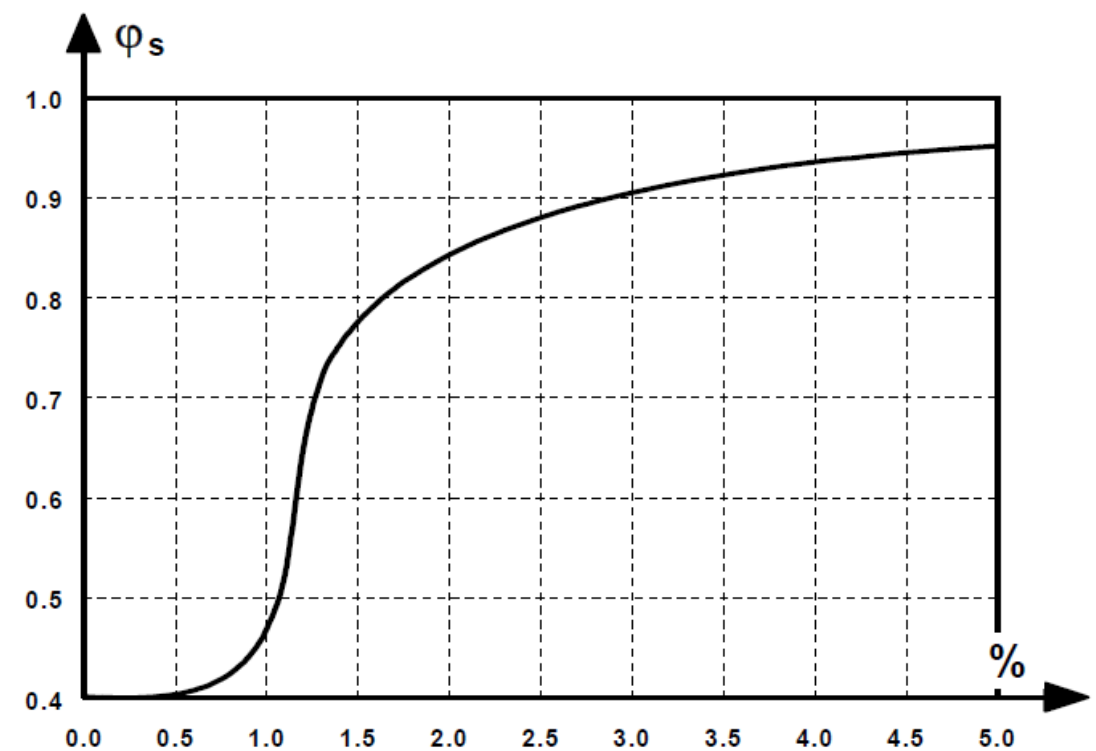

b)

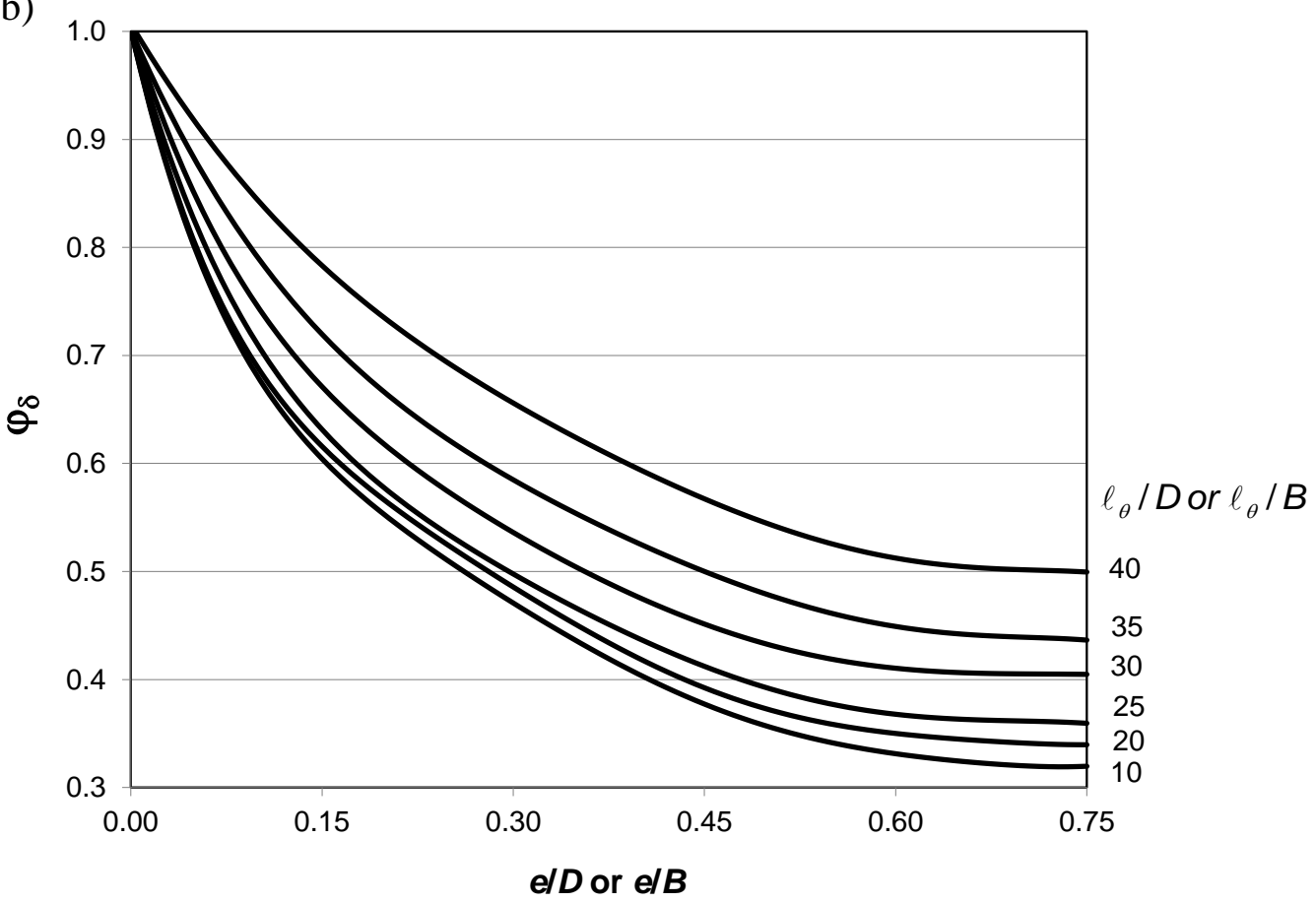

Fig. 8. Correction coefficients from Section H.4 in Annex H [12]: a) Coefficient depending on the percentage of reinforcement; b) Coefficient depending on the eccentricity (extrapolated to $e / D=0.75)$ 


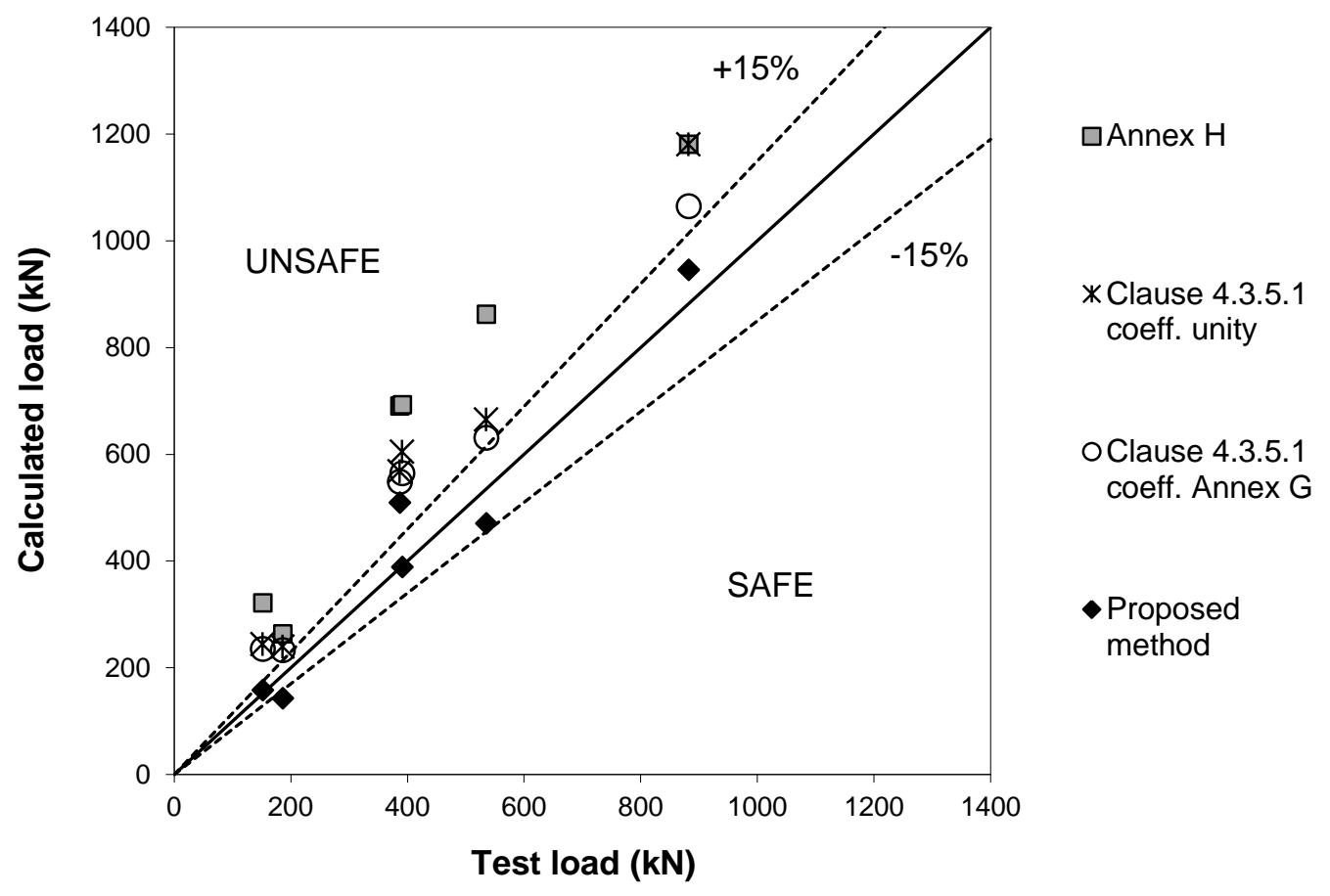

Fig. 9. Comparison between calculated buckling load and test load, circular columns 


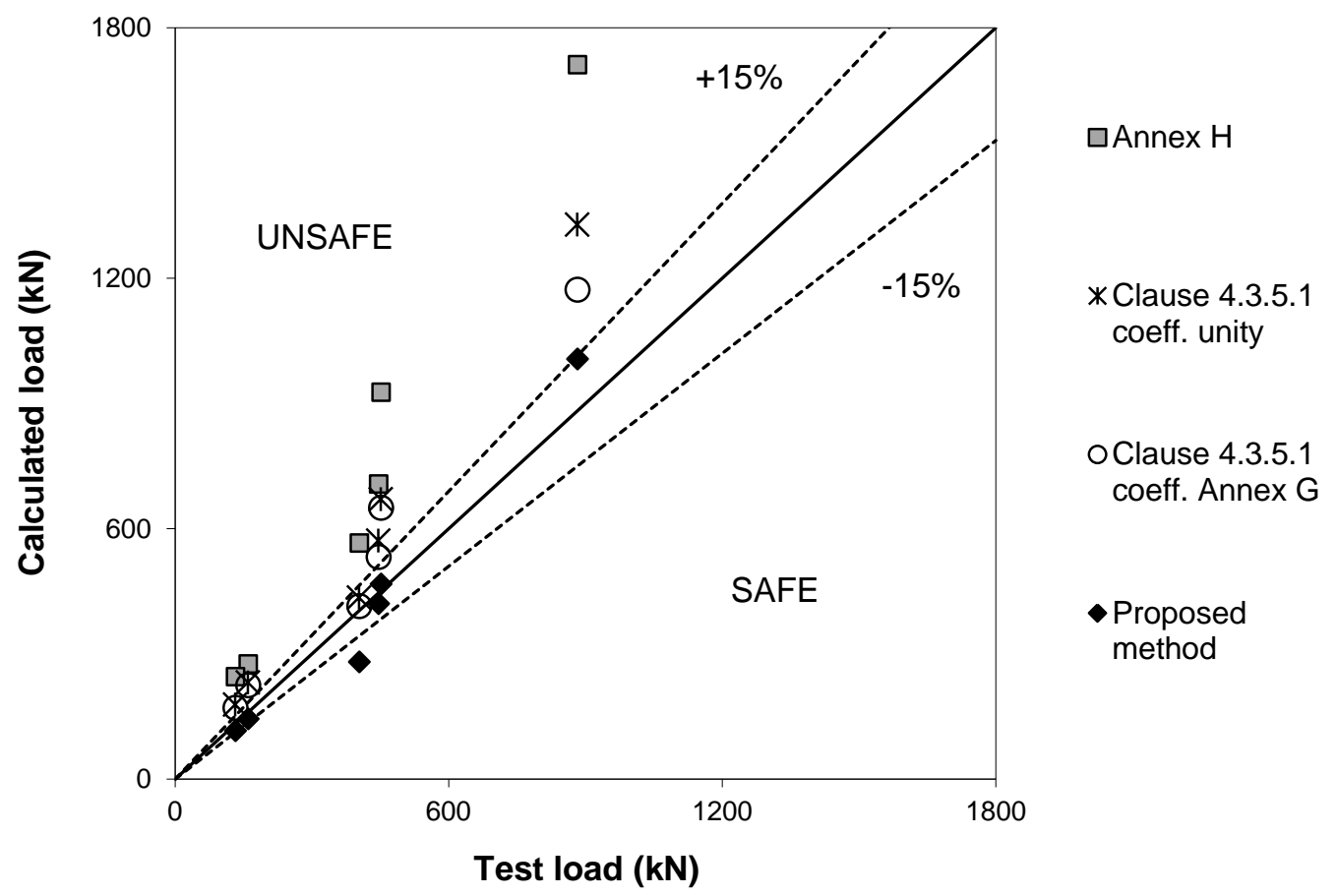

Fig. 10. Comparison between calculated buckling load and test load, square columns 
Table 1. Test properties and results, circular columns

\begin{tabular}{cccccccccccc}
\hline No. & $\boldsymbol{D}(\mathbf{m m})$ & $\boldsymbol{t}(\mathbf{m m})$ & Reinf. & $\begin{array}{c}\boldsymbol{\rho} \\
(\boldsymbol{\%})\end{array}$ & $\boldsymbol{e} \boldsymbol{D}$ & $\begin{array}{c}\boldsymbol{f}_{\mathrm{c}} \\
(\mathbf{M P a})\end{array}$ & $\begin{array}{c}\boldsymbol{f}_{\mathbf{y}} \\
(\mathbf{M P a})\end{array}$ & $\begin{array}{c}\boldsymbol{f}_{\mathrm{s}} \\
(\mathbf{M P a})\end{array}$ & $\bar{\lambda}$ & $\begin{array}{c}\text { Load } \\
(\mathbf{k N})\end{array}$ & $\begin{array}{c}\text { Time } \\
(\mathbf{m i n})\end{array}$ \\
\hline $\mathrm{C} 1$ & 193.7 & 8 & $6 \phi 12$ & 2.74 & 0.5 & 36.4 & 359.1 & 512.4 & 0.75 & 186.65 & 26 \\
$\mathrm{C} 2$ & 273 & 10 & $6 \phi 16$ & 2.40 & 0.5 & 37.6 & 369.7 & 553.5 & 0.54 & 387.46 & 30 \\
$\mathrm{C} 3$ & 193.7 & 8 & $6 \phi 12$ & 2.74 & 0 & 43.2 & 359.1 & 512.4 & 0.76 & 535.57 & 29 \\
$\mathrm{C} 4$ & 273 & 10 & $6 \phi 16$ & 2.40 & 0 & 37.8 & 451.1 & 553.5 & 0.57 & 882.90 & 72 \\
$\mathrm{C} 5$ & 193.7 & 8 & $6 \phi 16$ & 4.86 & 0.75 & 35.8 & 359.1 & 553.5 & 0.77 & 152.41 & 29 \\
$\mathrm{C} 6$ & 273 & 10 & $8 \phi 20$ & 5.00 & 0.5 & 36.9 & 369.7 & 566.5 & 0.56 & 391.53 & 57 \\
\hline
\end{tabular}

Table 2. Test properties and results, square columns

\begin{tabular}{|c|c|c|c|c|c|c|c|c|c|c|c|}
\hline No. & $B(\mathbf{m m})$ & $t(\mathbf{m m})$ & Reinf. & $\begin{array}{c}\rho \\
(\%)\end{array}$ & $e / B$ & $\begin{array}{c}f_{\mathrm{c}} \\
(\mathrm{MPa})\end{array}$ & $\begin{array}{c}f_{\mathbf{y}} \\
(\mathbf{M P a})\end{array}$ & $f_{\mathrm{s}}(\mathbf{M P a})$ & $\bar{\lambda}$ & $\begin{array}{c}\text { Load } \\
(\mathbf{k N})\end{array}$ & $\begin{array}{l}\text { Time } \\
\text { (min) }\end{array}$ \\
\hline S1 & 150 & 8 & $4 \phi 12$ & 2.52 & 0.5 & 45.0 & 452.7 & 548 & 0.91 & 161.13 & 26 \\
\hline $\mathrm{S} 2$ & 220 & 10 & $4 \phi 16+4 \phi 10$ & 2.80 & 0.5 & 39.7 & 560.3 & $\begin{array}{c}527(\phi 16) \\
575.25(\phi 10)\end{array}$ & 0.66 & 446.53 & 23 \\
\hline S3 & 150 & 8 & $4 \phi 12$ & 2.52 & 0 & 43.2 & 452.7 & 548 & 0.90 & 404.29 & 32 \\
\hline S4 & 220 & 10 & $4 \phi 16+4 \phi 10$ & 2.80 & 0 & 42.4 & 560.3 & $\begin{array}{c}527(\phi 16) \\
575.25(\phi 10)\end{array}$ & 0.66 & 882.90 & 54 \\
\hline S5 & 150 & 8 & $8 \phi 12$ & 5.04 & 0.75 & 48.7 & 452.7 & 548 & 0.94 & 133.18 & 29 \\
\hline S6 & 220 & 10 & $4 \phi 20+4 \phi 16$ & 5.15 & 0.5 & 38.8 & 560.3 & $\begin{array}{l}576(\phi 20) \\
527(\phi 16) \\
\end{array}$ & 0.67 & 452.63 & 29 \\
\hline
\end{tabular}


Table 3. Comparison with EC4 and proposed method, circular columns

a) Correction to account for eccentricity from section H.4 in Annex $\mathrm{H}$

\begin{tabular}{|c|c|c|c|c|c|c|c|c|c|}
\hline & \multirow[b]{3}{*}{$N(\mathbf{k N})$} & \multirow{2}{*}{\multicolumn{2}{|c|}{ Annex H }} & \multicolumn{4}{|c|}{ Clause 4.3.5.1 } & \multirow{2}{*}{\multicolumn{2}{|c|}{ Proposed method }} \\
\hline & & & & \multicolumn{2}{|c|}{ Coeff. $\varphi_{i, \theta}$ unity } & \multicolumn{2}{|c|}{ Coeff. $\varphi_{i, \theta}$ Annex G } & & \\
\hline & & $N_{f i, R d}(\mathbf{k N})$ & $N / N_{f i, R d}$ & $N_{f i, R d}(\mathbf{k N})$ & $N / N_{f i, R d}$ & $N_{f i, R d}(\mathbf{k N})$ & $N / N_{f i, R d}$ & $N_{f i, R d}(\mathbf{k N})$ & $N / N_{f i, R d}$ \\
\hline $\mathrm{C} 1$ & 186.65 & 263.45 & 0.71 & 239.22 & 0.78 & 232.51 & 0.80 & 142.48 & 1.31 \\
\hline $\mathrm{C} 2$ & 387.46 & 690.03 & 0.56 & 567.60 & 0.68 & 548.44 & 0.71 & 509.28 & 0.76 \\
\hline $\mathrm{C} 3$ & 535.57 & 862.10 & 0.62 & 665.20 & 0.81 & 630.98 & 0.85 & 470.55 & 1.14 \\
\hline $\mathrm{C} 4$ & 882.90 & 1180.63 & 0.75 & 1180.37 & 0.75 & 1064.11 & 0.83 & 945.03 & 0.93 \\
\hline C5 & 152.41 & 320.99 & 0.47 & 244.49 & 0.62 & 234.74 & 0.65 & 157.94 & 0.97 \\
\hline \multirow[t]{3}{*}{ C6 } & 391.53 & 692.43 & 0.57 & 604.40 & 0.65 & 564.47 & 0.69 & 388.14 & 1.01 \\
\hline & & Mean & 0.61 & Mean & 0.71 & Mean & 0.76 & Mean & 1.02 \\
\hline & & Std. dev. & 0.10 & Std. dev. & 0.07 & Std. dev. & 0.08 & Std. dev. & 0.19 \\
\hline
\end{tabular}

b) Correction to account for eccentricity from section G.7 in Annex G

\begin{tabular}{|c|c|c|c|c|c|c|c|c|c|}
\hline & \multirow[b]{3}{*}{$N(\mathbf{k N})$} & \multirow{2}{*}{\multicolumn{2}{|c|}{ Annex H }} & \multicolumn{4}{|c|}{ Clause 4.3.5.1 } & \multirow{2}{*}{\multicolumn{2}{|c|}{ Proposed method }} \\
\hline & & & & \multicolumn{2}{|c|}{ Coeff. $\varphi_{i, \theta}$ unity } & \multicolumn{2}{|c|}{ Coeff. $\varphi_{i, \theta}$ Annex $\mathbf{G}$} & & \\
\hline & & $N_{f i, R d}(\mathbf{k N})$ & $N / N_{f i, R d}$ & $N_{f i, R d}(\mathbf{k N})$ & $N / N_{f i, R d}$ & $N_{f i, R d}(\mathbf{k N})$ & $N / N_{f i, R d}$ & $N_{f i, R d}(\mathbf{k N})$ & $N / N_{f i, R d}$ \\
\hline $\mathrm{C} 1$ & 186.65 & 263.07 & 0.71 & 238.88 & 0.78 & 232.18 & 0.80 & 142.28 & 1.31 \\
\hline $\mathrm{C} 2$ & 387.46 & 721.46 & 0.54 & 593.46 & 0.65 & 573.43 & 0.68 & 532.48 & 0.73 \\
\hline C3 & 535.57 & 862.10 & 0.62 & 665.20 & 0.81 & 630.98 & 0.85 & 470.55 & 1.14 \\
\hline $\mathrm{C} 4$ & 882.90 & 1180.63 & 0.75 & 1180.37 & 0.75 & 1064.11 & 0.83 & 945.03 & 0.93 \\
\hline $\mathrm{C} 5$ & 152.41 & 266.51 & 0.57 & 202.99 & 0.75 & 194.90 & 0.78 & 131.13 & 1.16 \\
\hline \multirow[t]{3}{*}{ C6 } & 391.53 & 673.19 & 0.58 & 587.61 & 0.67 & 548.79 & 0.71 & 377.36 & 1.04 \\
\hline & & Mean & 0.63 & Mean & 0.73 & Mean & 0.78 & Mean & 1.05 \\
\hline & & Std. dev. & 0.08 & Std. dev. & 0.06 & Std. dev. & 0.07 & Std. dev. & 0.20 \\
\hline
\end{tabular}


Table 4. Comparison with EC4 and proposed method, square columns

a) Correction to account for eccentricity from section H.4 in Annex $\mathrm{H}$

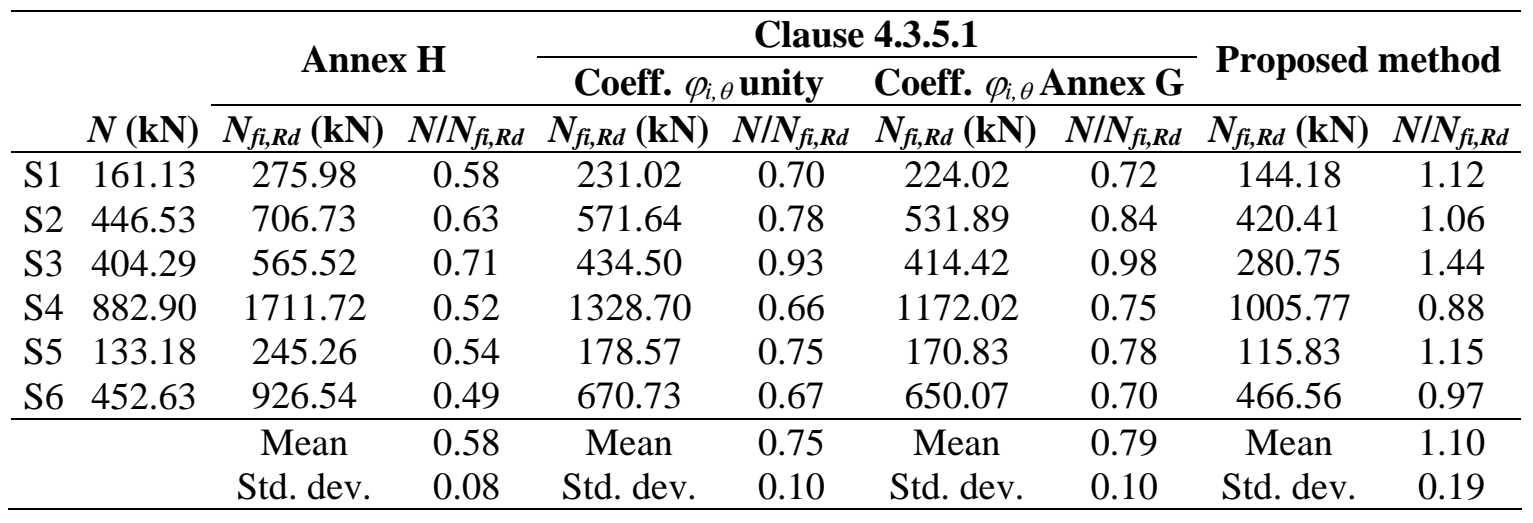

b) Correction to account for eccentricity from section G.7 in Annex G

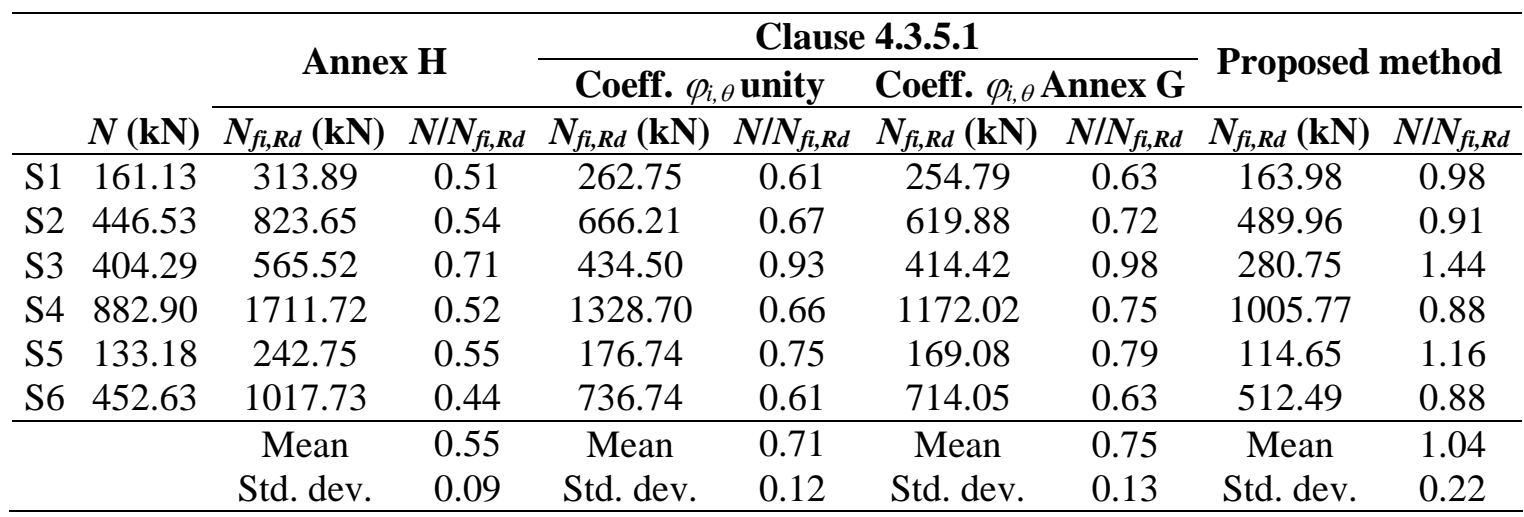




\section{LIST OF FIGURE CAPTIONS}

Fig. 1. Cross-sectional dimensions and reinforcement arrangement of the tested columns

Fig. 2. a) Schematic view of the column inside the furnace; b) thermocouple locations (circular columns)

Fig. 3. Evolution of temperatures at mid-height section (A-A'), for column C4.

Fig. 4. Square column fire test: a) preparation of the column specimen; b) column after test; c) schematic view of the knife-edge; d) detail of the eccentricity at the bottom end of the column

Fig. 5. Results of the fire tests on circular columns: a) CHS $193.7 \times 8 \mathrm{~mm}$; b) CHS $273 \times 10$ $\mathrm{mm}$

Fig. 6. Results of the fire tests on square columns: a) SHS $150 \times 8 \mathrm{~mm}$; b) SHS $220 \times 10 \mathrm{~mm}$

Fig. 7. Comparison between the different circular and square columns tested: a) Steel area; b) Fire resistance time; c) Applied load; d) Member slenderness

Fig. 8. Correction coefficients from Section H.4 in Annex H [12]: a) Coefficient depending on the percentage of reinforcement; b) Coefficient depending on the eccentricity (extrapolated to $e / D=0.75$ )

Fig. 9. Comparison between calculated buckling load and test load, circular columns

Fig. 10. Comparison between calculated buckling load and test load, square columns

\section{LIST OF TABLE CAPTIONS}

Table 1. Test properties and results, circular columns

Table 2. Test properties and results, square columns

Table 3. Comparison with EC4 and proposed method, circular columns

Table 4. Comparison with EC4 and proposed method, square columns 